\title{
Fatal new onset Congestive Heart Failure related to Adalimumab use in a patient with relapsing Hidradenitis Suppurativa: A case report.
}

Claudia Mansitó López ${ }^{1}$, Paola Torres Laboy ${ }^{2}$, Miguel Ortiz Bou ${ }^{1}$, Aida Quintero Noriega ${ }^{3}$, and Vielka Cintrón Rivera ${ }^{1}$

${ }^{1}$ Manati Medical Center

${ }^{2}$ Ponce Health Sciences University

${ }^{3}$ University of Puerto Rico

July 20, 2020

\begin{abstract}
67-year-old male with a history of hidradenitis suppurativa (HS) came to our hospital complaining symptoms of decompensated heart failure of 2 weeks of evolution after the re-initiation of adalimumab for his HS. Other causes of heart failure were ruled out. Unfortunately, the patient died secondary to heart failure and septicemia.
\end{abstract}

\section{Hosted file}

Manuscript.pdf available at https://authorea.com/users/344451/articles/470973-fatal-newonset-congestive-heart-failure-related-to-adalimumab-use-in-a-patient-with-relapsinghidradenitis-suppurativa-a-case-report 